\title{
OS IMPACTOS NA MÃO DE OBRA - TERCEIRIZAÇÃO NA ATIVIDADE-FIM - LEI 13.429 /2017
}

\author{
Cláudia da Silva, Olivie Samuel Paião, Mari Angela \\ Universidade do Oeste Paulista - UNOESTE, curso de Direito, Presidente Prudente, SP. \\ E-mail: silva-clau2014@bol.com.br
}

\begin{abstract}
RESUMO
A terceirização, em uma análise crítica, pós-regulamentação, foi o objetivo deste trabalho. Por ela, permite-se a contratação de trabalhadores para prestação de serviços para outro empregador, que não aquele que, efetivamente se beneficia do trabalho humano, inclusive na atividade principal e fim empresarial este último objeto central deste estudo. Muito embora já ocorresse a contratação de trabalhadores por empresas terceirizadas, fato comum no meio empresarial, tal modalidade se concentrava na atividade-meio. A inovação da pesquisa destaca-se pelo olhar diferenciado na realidade atual, em comparação com a anterior ausência de qualquer regulamentação. Apoiada em diretrizes advindas da jurisprudência dos tribunais cristalizada na Súmula 331 do Tribunal Superior do Trabalho, a nova opção legal é um desafio para o operador do direito. Por meio do método dedutivo, dialético e empírico, esta pesquisa doutrinária e jurisprudencial, revelou a tendência de maior precarização dos direitos dos trabalhadores com a liberação da terceirização na atividade-fim.
\end{abstract}

Palavras-Chave: Terceirização, Trabalhador, Atividade-fim, Precarização, Intermediação.

\section{IMPACTS IN THE HAND OF WORK - TERMINATION IN THE ACTIVITY-END - LEI 13.429 /2017}

\section{ABSTRACT}

Outsourcing, in a post-regulatory critical analysis, was the objective of this work. It allows the hiring of workers to provide services to another employer, other than the one that effectively benefits from human work, including the main activity and business purpose, the latter central object of this study. Although the hiring of outsourced workers had already occurred, a common fact in the business environment, this modality focused on the activity-middle. The innovation of research stands out for the different look in the current reality, compared to the previous absence of any regulation. Backed by guidelines from the jurisprudence of the courts crystallized in Summary 331 of the Superior Labor Court, the new legal option is a challenge for the operator of the law. By means of the deductive, dialectical and empirical method, this doctrinal and jurisprudential research revealed the tendency of greater precariousness of workers' rights with the liberation of outsourcing in the final activity.

Keywords: Outsourcing, Worker, Activity-end, Precariousness, Intermediation.

\section{INTRODUÇÃO}

Em passado recente, ante a ausência de legislação relativa à terceirização na seara trabalhista, o Brasil viveu (e por que não dizer, ainda vive) um crescimento desenfreado do fenômeno denominado terceirização, que, em definição simplista, trata-se da contratação de trabalhadores por uma empresa para fornecer a mão de obra humana, que irá prestar serviços em outra- denominada contratante-, a real beneficiária final da força de trabalho.

Segundo os estudiosos, a terceirização vem permitindo uma escalada rumo a um futuro incerto nas relações de trabalho que, anunciam os doutrinadores e juristas especialistas no Direito 
do Trabalho, não será nada benéfico à classe operária.

Em um primeiro momento, toda a sociedade brasileira, por meio da mídia, com reportagens encomendadas pelas entidades de classe que representam os empresários nacionais, passaram os anos de 2016 e início de 2017, assistindo propagandas televisivos e em outros meios de comunicação, para serem forçados a acreditar que o instituto da terceirização não traria maiores prejuízos aos trabalhadores, visto que, seus direitos alardeavam, estariam igualmente garantidos com a contratação direta, incluindo a carteira assinada, já que registrados numa dada empresa prestadora de serviços e ou fornecedora de mão de obra, supostamente com igualdade de direitos.

Era o que se noticiava no período anterior a aprovação do projeto de lei que se transformou na Lei no 13.429, de 31 de março de 2017. Contudo, não é assim que se mostra.

Não obstante a notícia no cenário promissor delineado, infelizmente, tratou-se de mais uma "publicidade enganosa" vendida ao trabalhador brasileiro. Passados quase 6 (seis) meses da edição da lei, as tais promessas, principalmente a de maior liberdade de contratação e geração de novos postos, não foram cumpridas. Não se forneceu nenhuma mudança ou posto efetivo de trabalho aos mais de 14 milhões de desempregados que esperam, aflitos, por uma oportunidade e uma vaga de emprego formal.

O parlamento, desprezando estudos feitos em comissões e discussões prévias com a sociedade, que clamavam ao menos pela responsabilidade solidária, votou à toque de caixa outro projeto, que tinha sido engavetado na década de 90, pois, assustadoramente, numa cochilada, a terceirização com responsabilidade solidária, havia passado no projeto a ser votado e encaminhado da Câmara dos Deputados para o Senado Federal.

Numa manobra política vergonhosa, o Senado da República, desengavetou um projeto antigo e votou todo o conteúdo diverso, sem alterações, para evitar retorno à Câmara dos Deputados e, sem escrúpulos, impôs ao operariado nacional o abandono total à própria sorte, inclusive os que prestam e prestarão serviços nas três esferas do governo (federal, estadual e municipal), sem qualquer responsabilidade pelas dívidas trabalhistas, pois, foi essa a opção do legislador para os terceirizados, incrustrados aos milhares em instituições públicas, e aos empresários brasileiros, apenas a responsabilidade secundária ou subsidiária (só pode ser cobrada uma dívida após esgotados todos os meios cabíveis contra o devedor principal), neste caso, a empresa terceirizada em primeiro lugar, e só ao final a empresa contratante, ou tomadora de serviços.

Assim, entendemos que, os empregadores menos preocupados com o crescimento individual de seus trabalhadores querem, com a terceirização, na verdade, livrar-se do chamado passivo trabalhista.

\section{METODOLOGIA}

Trata-se de uma reflexão embasada em bibliografia diversa, fundamentada em leituras, fichamentos de livros, periódicos, leis, decretos, jurisprudências, entre outros, mas principalmente em artigos jurídicos, via pesquisa eletrônica, tendo em vista a escassez de material sobre o tema muito recente decorrente da promulgação da lei em março do ano em curso.

O método indutivo foi o escolhido, saindo da investigação geral (os efeitos da terceirização restrita na atividade-meio), para a situação particular (liberada na atividade-fim) impactos decorrente na mão de obra, após a liberação da lei.

\section{DISCUSSÃO}

A terceirização se caracteriza por uma relação trilateral, envolvendo, portanto, três sujeitos: Empresa Fornecedora de mão de obra (empresa interposta); Empresa Tomadora (cliente da 
fornecedora) e o Trabalhador (empregado da empresa fornecedora). (BRASIL, 2017)

Como ensinam os doutrinadores, o trabalhador terceirizado, apesar de empregado da empresa fornecedora trabalha nas dependências da empresa tomadora. (CISNEIROS, 2016). Aqui há dependência no sentido de local de trabalho. Mas, a lei nova permite que seja fora das dependências da empresa contratante (tomadora dos serviços).

RESENDE (2016, p. 305) é esclarecedor ao definir a modalidade:

$\mathrm{Na}$ terceirização desloca-se o foco da tradicional relação bilateral entre empregador e empregado, criando verdadeira relação trilateral, abrangendo em um dos vértices do triângulo o trabalhador, que mantém vínculo de emprego com o prestador de serviços (terceiro ou empregador aparente), mas disponibiliza o resultado de sua energia de trabalho a um tomador de serviços (empregador real) diverso do seu empregador.

O professor Sergio Pinto Martins (2000, p.16) lembra que: "no Brasil, a noção de terceirização foi trazida por multinacionais na década de cinquenta, pelo interesse que tinham em se preocupar apenas com a essência do seu negócio."

O mesmo autor citado lembra que a indústria automobilística é exemplo de terceirização, ao contratar a prestação de serviços de terceiros para a produção de componentes do automóvel, reunindo peças fabricadas por aqueles e procedendo à montagem final do veículo, foram pioneiras no cenário nacional, em terceirização, mesmo fora das dependências das montadoras, posteriormente, trazendo o trabalhador terceirizado para o mesmo ambiente.

Mas a terceirização não ficou somente na economia privada. Como destaca Ricardo Resende (2016, p. 417): "A título de curiosidade histórica, somente a partir da década de 1970 a terceirização se enraizou no cotidiano brasileiro, primeiro com a descentralização dos serviços públicos preconizada pelo Decreto-Lei n ²00, de 1967."

Os artigos segundo e terceiro, já no início da lei mais importante no âmbito trabalhista, a CLT- Consolidação das Leis do Trabalho, que aliás sofreu alteração em cerca de 100 artigos recentemente (Lei 13.467/17), manteve a redação original da cabeça dos artigos referidos, primeiro conceituando quem é o empregador e depois o empregado (BRASIL, 2017):

Art. 20 - Considera-se empregador a empresa, individual ou coletiva, que, assumindo os riscos da atividade econômica, admite, assalaria e dirige a prestação pessoal de serviço.

[...]

Art. 3o - Considera-se empregado toda pessoa física que prestar serviços de natureza não eventual a empregador, sob a dependência deste e mediante salário.

Parágrafo único - Não haverá distinções relativas à espécie de emprego e à condição de trabalhador, nem entre o trabalho intelectual, técnico e manual. (grifos nossos)

O empregado terceirizado deve, portanto, nessa linha de raciocínio, respeitar as diretrizes passadas diretamente pela empresa que o contratou e a ela cabe dirigir a prestação de serviços e não os contratantes. Caso essa lógica fosse quebrada, a regra seria a declaração de nulidade da terceirização, considerada ilícita, e o judiciário, via de regra declarava a vinculação direta com o tomador de serviços, que arcaria com eventuais créditos trabalhistas pendentes e/ou indenizações por infrações cometidas ao longo do contrato de trabalho ilícito. 
Neste sentido, foi a redação da primeira jurisprudência sobre o assunto na mais alta corte trabalhista, cristalizada na Súmula no 256 do Tribunal Superior do Trabalho - TST, cancelada em 2003, portanto há quase 14 anos (BRASIL, 2003):

\section{CONTRATO DE PRESTAÇÃO DE SERVIÇOS. LEGALIDADE (cancelada) - Res. 121/2003, DJ 19, 20 e 21.11.2003 \\ Salvo os casos de trabalho temporário e de serviço de vigilância, previstos nas Leis nos 6.019, de 03.01.1974, e 7.102, de 20.06.1983, é ilegal a contra- tação de trabalhadores por empresa interposta, formando-se o vínculo empregatício diretamente com o tomador dos serviços.}

Consequentemente, como se queria regulamentar as atividades pertinentes a recém terceirização, tratou-se, então, de criar leis e decretos, dentre eles: decreto $n^{\circ} 1.212 / 66$ e 1.216/66, que permitia aos bancos a contratação de serviços de seguranças; decreto $n{ }^{\circ}$ $62.756 / 68$, que normatizou a criação e o funcionamento de agencias de colocação ou intermediação de mão de obra; decreto-lei $n^{\circ} 1.034 / 69$, que tratava de medidas de segurança, caixas econômicas e cooperativas de crédito; a lei $n^{\circ} 6.019 / 74$, que rege a contratação do trabalho temporário.

Contudo, a sociedade empresarial queria mais liberdade e, certamente, transferir e se eximir das responsabilidades. Assim, de tanto forçar teses por seus departamentos jurídicos, o TST, num suposto "avanço social", e em decorrência de tantos conflitos trabalhistas na terceirização (até porque o próprio judiciário que se utilizava de mão de obra terceirizada) teve que ceder ao entendimento do STF, que foi instado a se manifestar e se pronunciou.

Definiu a suprema corte nacional, a favor dos empresários e definiu novo rumo, contrariando a posição materializada na súmula 256 que foi revisada pela até então súmula 331 do TST, com a seguinte redação que foi sendo acrescida/revisada ao longo dos anos:

CONTRATO DE PRESTAÇÃO DE SERVIÇOS. LEGALIDADE (nova redação do item IV e inseridos os itens V e VI à redação) - Res. 174/2011, DEJT $\begin{array}{lllll}\text { divulgado em } & 27, & 30 & \mathrm{e} & \mathbf{3 1 . 0 5 . 2 0 1 1}\end{array}$ I - A contratação de trabalhadores por empresa interposta é ilegal, formando-se o vínculo diretamente com o tomador dos serviços, salvo no caso de trabalho temporário (Lei $\mathrm{n}$ - 6.019, de 03.01.1974). II - A contratação irregular de trabalhador, mediante empresa interposta, não gera vínculo de emprego com os órgãos da Administração Pública direta, indireta ou fundacional (art. 37, II, da CF/1988). III - Não forma vínculo de emprego com o tomador a contratação de serviços de vigilância (Lei no 7.102, de 20.06.1983) e de conservação e limpeza, bem como a de serviços especializados ligados à atividade-meio do tomador, desde que inexistente a pessoalidade e a subordinação direta. IV - O inadimplemento das obrigações trabalhistas, por parte do empregador, implica a responsabilidade subsidiária do tomador dos serviços quanto àquelas obrigações, desde que haja participado da relação processual e conste também do título executivo judicial. V - Os entes integrantes da Administração Pública direta e indireta respondem subsidiariamente, nas mesmas condições do item IV, caso evidenciada a sua conduta culposa no cumprimento das obrigações da Lei n.o 8.666, de 21.06.1993, especialmente na fiscalização do cumprimento 
das obrigações contratuais e legais da prestadora de serviço como empregadora. A aludida responsabilidade não decorre de mero inadimplemento das obrigações trabalhistas assumidas pela empresa regularmente

contratada. $\mathrm{VI}$ - A responsabilidade subsidiária do tomador de serviços abrange todas as verbas decorrentes da condenação referentes ao período da prestação laboral. (BRASIL, 2011)

As empresas brasileiras, claro, que já vinham forçando a terceirização, desde o final das décadas de 70/80, intensificaram a contratação de terceiros, muitos sem nenhuma idoneidade econômica e financeira.

Empresas "de fachada", comandadas por verdadeiros "laranjas" ou "testas de ferro" proliferam no Brasil, e seus dirigentes desaparecem ao primeiro indício de crise financeira. As aspas propositais indicam o jargão comum utilizado como uma espécie de gíria no âmbito empresarial e trabalhista para identificar empresas ou sócios sem nenhum patrimônio para garantir seus negócios.

Essas empresas e seus "testas de ferro" que, infelizmente, integram boa parte do processo de descentralização das atividades empresariais por meio da terceirização, antes autorizadas a atuar apenas nas atividades periféricas e secundárias, denominadas de "atividade-meio", com raras exceções, deram vez a lógica da má-fé, de modo que aumentou a abertura de empresas não idôneas, que atuaram sem risco algum, por exemplo, no caso de quebra, o sócio verdadeiro não responderia com o seu patrimônio na chamada teoria da desconsideração da pessoa jurídica, aliás imposta ao judiciário trabalhistas, no seio da nova reforma.

A fim de que, a responsabilidade pelos créditos trabalhistas recaísse sobre estas empresas de fachada. A avalanche de ações trabalhistas abarrotou a Justiça do Trabalho e os empregados, ditos terceirizados, amargaram durante muito tempo uma marcha processual ineficaz.

Na grande maioria destas ações, embora não haja estatística, ou pelo menos neste trabalho não se teve acesso, pelo que se denuncia na mídia, os empregadores terceirizados (empregador aparente e não de fato), não têm nenhuma capacidade de solver os créditos trabalhistas de seus empregados, além de ficarem dependentes das quantias repassadas pelos tomadores de serviços para dela se valer e repassar os salários de "seus" empregados.

Nesse contexto, todos os cuidados devem ser tomados no momento de se decidir pela terceirização de determinada atividade, não só em relação aos aspectos legais da contratação a ser levada a efeito, mas, principalmente, no que concerne a sua operacionalização.

Discutir e analisar os problemas da terceirização vividos pelos trabalhadores brasileiros, é um desafio duplo, provocado pela amplitude da lei nova em torno da problemática do que já existia, ou seja, a precarização das condições de trabalho terceirizado.

Às evidências que, a falsa esperança que alguns leigos tiveram de que a terceirização supostamente aumentaria o número de vagas de trabalho formal, em plena crise econômica, política, financeira e social, que assola o país, gerando consequências, principalmente, no número de desempregados e em torno das relações do trabalho mercantilizado, em razão da maioria da população brasileira não entender a crise econômica e os efeitos nefastos da globalização, como pode-se observar nas palavras de Cassar:

A globalização e a crise econômica mundial tornaram o mercado interno mais frágil, exigindo maior produtividade por menores custos para melhor competir com o mercado externo. O primeiro atingido com essa urgente necessidade de redução de custos foi o trabalhador, que teve vários direitos 
flexibilizados e outros revogados. A terceirização é apenas uma das formas que os empresários têm buscado para amenizar seus gastos, reinvestindo no negócio ou aumentando seus lucros. Daí por que dos anos 90 para cá a locação de serviços ou terceirização tem sido moda. (CASSAR, 2015, p. 236)

O trabalhador por ser o elo mais fraco da relação de trabalho e emprego e por necessitar, aceita, mesmo que de forma precária, as condições pré-estabelecidas pelo empregador, mesmo que isso the custe redução salarial e diminuição dos direitos trabalhistas negociados com a empresa tomadora de serviços para os poucos trabalhadores diretos que mantém, até porque o enquadramento sindical, que deveria ser o mesmo, passa a ser discutível.

Neste trabalho, a reflexão crítica que se faz, sob a ótica da nova lei 13.429/2017, conjuntamente com a súmula 331 do TST, numa confrontação de uma involução, e não evolução, a experiência empírica e a fala dos juristas que entendem melhor do assunto, demonstram que especialistas enxergam um cenário tenebroso para a liberação da terceirização na atividade fim.

Basta um breve confronto com a disposição da súmula 331 que mal ou bem regulamentava com senso de justiça mediano, a terceirização, e a redação atual para se ter uma ideia do tamanho do prejuízo que se tem pela frente, inclusive a permissão de "quarteirização" ou subcontratação de uma outra empresa pela primeira terceirizada. Eis a nova redação, da Lei 13.429/2017:

$4^{\circ}$-A. Empresa prestadora de serviços a terceiros é a pessoa jurídica de direito privado destinada a prestar à contratante serviços determinados e específicos

$\S 1^{\underline{0}}$ A empresa prestadora de serviços contrata, remunera e dirige o trabaIho realizado por seus trabalhadores, ou subcontrata outras empresas para realização desses serviços

$\S 2^{\circ}$ Não se configura vínculo empregatício entre os trabalhadores, ou sócios das empresas prestadoras de serviços, qualquer que seja o seu ramo, $\mathrm{e}$ a empresa contratante. (grifos nossos)

Nesta toada, a reflexão que se chega, até em razão da justificada escassez de doutrina sobre o tema, após a edição da lei, por parte de um dos mais ferrenhos críticos da nova lei, professor do Curso de Direito da Universidade de São Paulo, cujo texto é esclarecedor, fala por si só, e vai ao encontro da conclusão deste trabalho, no apontamento das falhas anteriores e sua provável repetição num futuro próximo, pois tais fatos, relativos a inegável precarização dos direitos dos trabalhadores terceirizados, já ocorriam ao tempo em que a jurisprudência da Súmula 331, apenas permitia terceirização na atividade-meio:

Eis as primeiras impressões de Gustavo Filipe Barbosa Garcia:

A Lei 13.429/2017 não restringe a sua incidência à esfera privada, podendo dar margem ao entendimento de que as suas previsões sobre terceirização podem ser aplicadas, em tese, também à administração pública, desde que sejam observadas as disposições específicas a respeito, como a exigência de licitação na contratação de serviços. O art. 40-A da Lei 6.019/1974, acrescentado pela Lei $13.429 / 2017$, passa a prever que empresa prestadora de serviços a terceiros é a pessoa jurídica de direito privado destinada a prestar à contratante "serviços determinados e específicos". A empresa prestadora de serviços a terceiros, assim, não pode ser pessoa física, nem 
mesmo um empresário individual, devendo ser necessariamente pessoa jurídica. A expressão "serviços determinados e específicos" revela que a terceirização só é admitida quanto a serviços delimitados previamente e especificados. Vale dizer, a empresa prestadora de serviço não pode prestar serviços genéricos, não se admitindo a terceirização, pela empresa contratante (tomadora), de atividades sem especificação. A menção a "serviços determinados e específicos", de certa forma, faz lembrar a previsão da CLT a respeito dos contratos de trabalho a prazo determinado. Efetivamente, o art. 443, § 10, da CLT dispõe que se considera como de prazo determinado o contrato de trabalho cuja vigência dependa de termo prefixado ou da execução de serviços especificados ou ainda da realização de certo acontecimento suscetível de previsão aproximada. No contrato de trabalho a prazo determinado o empregador contrata o empregado diretamente, inclusive para realizar atividades inerentes à sua atividade empresarial. Com isso, torna-se possível o entendimento de que a terceirização, desde que seja de serviços delimitados e especificados, pode dizer respeito às atividades essenciais da contratante, ou seja, integrantes de seu objetivo social. Em outras palavras, com a Lei 13.429/2017, para certa corrente, permite-se concluir que a chamada atividade-fim da empresa tomadora pode ser terceirizada para uma empresa prestadora especializada, respeitando-se a exigência de que os serviços sejam determinados e específicos. A questão, entretanto, certamente apresentará controvérsias, sabendo-se que a jurisprudência, em regra, admite a terceirização apenas de serviços de vigilância, de conservação, limpeza e de atividades-meio da empresa tomadora, sendo assim consideradas aquelas acessórias, de suporte ou periféricas à atividade principal. Nesse sentido, segundo a Súmula 331 item III, do TST: "Não forma vínculo de emprego com o tomador a contratação de serviços de vigilância (Lei no 7.102, de 20.06.1983) e de conservação e limpeza, bem como a de serviços especializados ligados à atividade-meio do tomador, desde que inexistente a pessoalidade e a subordinação direta". (GARCIA, 2017, p. 416)

\section{CONCLUSÃO}

Como alertavam os juristas, conforme pontuado no início do trabalho, a precarização que se anunciava, continuará a existir, agora em larga escala. Caberá ao intérprete da lei, fazer valer os direitos dos trabalhadores, impedindo que a lei, votada sem nenhuma discussão nas últimas décadas, fruto de uma manobra política ardilosa, encontre um freio jurídico, inclusive por meio dos princípios que protegem o trabalhador e inspiraram a criação da Justiça do Trabalho.

A realidade no mundo do trabalho impôs novas formas de contratação, e a terceirização da mão de obra foi uma solução, ainda que em prejuízo ao trabalhador, escolhida pelo empresariado mundial em geral, e no Brasil em particular, agora sob o manto legal da recente lei aprovada, de legalidade duvidosa, mas que deve impor novo ritmo, nas contratações.

O empresário mais cauteloso, certamente aguardará o desenrolar das interpretações, pois, conforme estudado, ao contrário do que se poderia imaginar, apesar da manobra legislativa, o judiciário ainda é a última trincheira do cidadão em geral e a Justiça do Trabalho, do trabalhador em particular.

\section{REFERÊNCIAS BIBLIOGRÁFICAS}

DELGADO, Mauricio Godinho. Curso de direito do trabalho / Mauricio Godinho Delgado. - 15. Ed. 
- São Paulo: LTr, 2016.

GARCIA, Gustavo Filipe Barbosa. Curso de direito do trabalho. 11. ed. Rio de Janeiro: Forense, 2017.

Martins, Sergio Pinto. Direito do Trabalho. 32. ed. - São Paulo: Saraiva, 2016.

GARCIA, Gustavo Filipe Barbosa. Lei da terceirização não é clara quanto à permissão para atividade-fim. Artigo jurídico. Site Conjur.

http://www.conjur.com.br/2017-abr-02/gustavo-garcia-lei-nao-clara-quanto-permissao-atividadefim Acesso em: 16 ago. 2017.

LIMA, Francisco Meton Marques, LIMA, Francisco Péricles Rodrigues de Lima. REFORMA

TRABALHISTA. Entenda Ponto a Ponto. 1a ed. São Paulo: Ltr, 2017

Lei no 13.429, de 31 de março de 2017. Diário Oficial [da] República Federativa do Brasil. Poder Executivo, Brasília, DF, 31 de março de 2017. Disponível em:

http://www.planalto.gov.br/ccivil_03/_ato2015-2018/2017/lei/L13429.htm. Acesso em: 14 ago. 2017. 